\title{
ANÁLISE DA ATIVIDADE PRODUTIVA EM UMA EMPRESA METALÚRGICA - O GARGALO NA FABRICAÇÃO DAS ESCADAS
}

\section{ANALYSIS OF THE PRODUCTIVE ACTIVITY IN A METALLURGIC COMPANY - THE BOTTLENECK IN THE STAIRS MANUFACTURE}

\author{
Claudete Fogliato Ribeiro ${ }^{1}$; Adriane Guarienti²; Márcia Trojan Poll³; João Hélvio R. Oliveira ${ }^{4}$ \\ ${ }^{1}$ Universidade Federal de Santa Maria - UFSM - Santa Maria - Brasil - claufr@ @rterra.com.br \\ ${ }^{2}$ Universidade Federal de Santa Maria - UFSM - Santa Maria - Brasil - adrig.sm@ terra.com.br \\ ${ }^{3}$ Universidade Federal de Santa Maria - UFSM - Santa Maria - Brasil - marcia@ mor.com.br \\ ${ }^{4}$ Universidade Federal de Santa Maria- UFSM- Santa Maria - Brasil - jholive@ @terra.com.br
}

\begin{abstract}
Resumo
O presente estudo tem como principal objetivo apresentar uma proposta de melhoria associado ao processo produtivo das escadas de aço e alumínio produzidas em uma empresa metalúrgica, focando a redução e até mesmo a eliminação de gargalos. O método de pesquisa adotado caracteriza-se com sendo exploratória e descritiva, no levantamento dos dados utilizou-se da observação e análise no setor de produção da empresa, bem como entrevistas ao gerente de produção, que serviram de suporte para se chegar aos resultados obtidos. Através da análise dos dados foi possível o desenvolvimento de alternativas de melhoria. Mas cabe a direção da empresa a escolha da melhor proposta, de ordem econômica e operacional. Além de atingir o objetivo proposto o referido estudo proporcionou o confronto da teoria com a prática organizacional, um aspecto de suma importância para o aprendizado na vida acadêmica.
\end{abstract}

Palavras-chave: Produção; Gargalo; Alternativa de Melhoria.

\section{Introdução}

A competitividade das empresas na atualidade está associada à habilidade de gerar valor ao cliente através de uma relação custo-qualidade-tempo. O macro e microfluxo de produção são, nas empresas manufatureiras, vital para a conquista de vantagens sustentáveis, uma vez que grande parte dos custos são incorridos neste processo. Sabedores disto, os gestores e estudiosos têm procurado descobrir meios que proporcionem reais retornos ao processo produtivo em sua totalidade.

A empresa metalúrgica, objeto deste estudo, foca suas atividades na indústria e comércio de produtos para casa e lazer. Com mais de 40 anos em atividade, conquistando os mais exigentes mercados. A empresa comercializa uma vasta linha de produtos como: cadeiras, piscinas de PVC, churrasqueiras, escadas, produtos de camping, espetos e grelhas, varais, tábuas de passar roupa, panelas e produtos importados (gazebos, barracas, guarda-sóis, infláveis, entre outros). Ela atende 
os mais variados tipos de público, unindo a praticidade e a qualidade de seus produtos. Além de comercializar seus produtos em todo o território nacional, a empresa exporta cerca de $20 \%$ de sua produção para países que compõem o MERCOSUL e México.

Os objetivos deste trabalho foram conhecer a realidade empresarial, fazer uma análise em um dos processos de produção da empresa, a fim de observar a existência de um gargalo e propor, se possível, sugestões para eliminar o mesmo. Pode-se fazer um estudo aprofundado do assunto através da pesquisa bibliográfica e da visita à empresa com a finalidade de comparar a teoria com a prática organizacional. Na observação à fábrica foram coletados dados e informações, através de uma entrevista e com a dedicação e conhecimento da engenheira de projetos, foi possível ter uma visão clara de um gargalo na fabricação das escadas de aço e alumínio (de diversos tamanhos - 3 a 8 degraus), o que se tornou foco deste estudo. As atividades desenvolvidas por uma empresa visando atender seus objetivos de curto, médio e longo prazo se inter-relacionam muitas vezes de forma complexa. Compete à administração da produção a gestão eficaz dessas atividades: transformar insumos em produtos ou serviços acabados agregando valor ao produto final. Critérios competitivos como baixo custo, alta qualidade, entrega eficiente, flexibilidade e atendimento são aspectos que interferem no processo de formulação da estratégia de produção e operação justificando a necessidade de um estudo mais profundo e analítico do processo como um todo.

\section{Revisão da literatura}

Este capítulo destina-se à revisão de literatura, no que diz respeito à fundamentação teórica adotada para abordar o tema. Constituiu-se, através da metodologia de pesquisa bibliográfica, uma estrutura conceitual que proporciona a sustentação necessária ao desenvolvimento do presente estudo.

O estudo dos fatores necessários para se conhecer a realidade e as necessidades ligadas à produção, e que deverão ser trabalhadas para chegar à concretização dos objetivos da empresa. Os fatores do ambiente externo estão fora do controle direto da empresa, mas são essenciais para a reflexão da tendência do mercado. Os fatores do ambiente interno são mais flexíveis e deverão se adaptar às estratégias de planejamento da produção, e sucintamente serão abordados nos tópicos a seguir.

\subsection{Sistemas de produção}

Algumas empresas fabricam muitos produtos, enquanto outras fabricam poucos produtos diferentes. No entanto, cada uma utiliza diversos maquinários, equipamentos, processos, habilidades de trabalho e materiais. Para ser lucrativa, uma empresa deve organizar todos esses 
fatores para fabricar os produtos certos no tempo certo com o mais alto nível de qualidade e economia, atendendo as necessidades do consumidor.

Segundo Russomano (2000) Just in time é uma filosofia que se concentra na eliminação de desperdício no processo de manufatura. Ele exige que a administração faça todo o possível para ter as peças certas no lugar certo, no tempo certo e exatamente na quantidade certa, ou seja, nem mais, nem menos. O sistema visa administrar a manufatura de forma simples e eficiente, otimizando o uso dos recursos de capital, equipamento e mão-de-obra. O resultado é um sistema de manufatura capaz de atender às exigências de qualidade e entrega de um cliente ao menor custo. A filosofia do "JIT" é eliminar perdas. Nada deverá ser feito na produção que não adicione valor ao produto, diretamente associado com a transformação do material à sua forma desejada. A meta requer concentração no processo físico da própria produção.

Os sistemas de produção, de acordo com Moreira (2000), são classificados em função do fluxo do produto e são agrupados em geral em três categorias:

a) Sistema de Produção contínua ou fluxo em linha, cujo processo é focalizado no produto, apresenta uma sequiência linear em sua produção. Os produtos seguem uma seqüência prevista com uma alta eficiência e acentuada inflexibilidade. Apresenta-se de duas formas: produção em massa (tipo linha de montagem) e processamento contínuo (indústrias de processo).

b) Sistema de Produção intermitente, cujo foco é no processo, apresenta uma produção feita em lotes ou por encomenda. O produto flui de forma irregular de um centro de trabalho a outro e o equipamento é do tipo genérico, adaptando-se as características das diversas operações que estejam sendo feitos no produto. Este sistema apresenta a flexibilidade como vantagem fundamental, mesmo perdendo em volume de produção em relação ao sistema contínuo.

c) Sistema de Projeto Especial é aquele nos qual não existe um fluxo do produto ou de produção, constituindo-se em geral num único produto, seguindo uma seqüência de tarefas ao longo do temo, em geral de longa duração. Existe uma profunda correlação entre o sistema de produção, seu processo, e o produto, tanto que a mudança de um desses exige a adaptação do outro de forma dinâmica. (MOREIRA, 2000).

\subsection{Arranjo físico (layout)}

O arranjo físico de uma operação produtiva preocupa-se com o posicionamento físico dos recursos de "transformação", e é um importante instrumento dentro da empresa. Tem como objetivo: melhorar a produção e sua visualização, permitindo uma melhor movimentação de pessoal, equipamentos e produtos. Conseqüentemente, reduz o tempo e o custo para a organização. 
Layout é a melhor utilização do espaço disponível, que possibilita um processamento mais efetivo através da menor distância no menor tempo possível, resultando assim em um trabalho eficaz.

Segundo Slack et al (1999, p.160), “O arranjo físico de uma operação produtiva preocupa-se com a localização física dos recursos de transformação". O arranjo físico ou layout decide onde serão colocados as instalações, máquinas, equipamentos e pessoal envolvidos na produção, determinando com isso a forma e a aparência de uma operação produtiva. O layout também determina a maneira pela quais os recursos transformados, como materiais, informações e clientes fluem através da operação (SLACK et al, 1999).

Para a elaboração do layout são necessárias algumas informações como, por exemplo: a especificação do produto, características do produto, quantidades de produtos a produzir e matérias primas, seqüência da operação, espaço necessário para os equipamentos, informações sobre recebimento, estocagem de matérias-primas e dos produtos acabados. A finalidade do layout é essencialmente a capacidade de produzir produtos rapidamente e entregá-los no tempo certo, conforme Gaiter e Irazier (2001).

Tendo isto definido, segue-se para as seguintes etapas de elaboração do layout: definir qual dos tipos básicos de layout, será utilizado, planejamento, desenvolvimento; apresentação clara da visualização do layout; utilização da experiência de todos; e finalmente sua implantação. O planejamento do arranjo físico é recomendável a qualquer empresa, grande ou pequena. Com um bom arranjo físico obtêm-se resultados surpreendentes na redução de custos de operação e no aumento da produtividade e eficiência.

Na implantação de uma nova empresa, esse planejamento é imprescindível, mas naquelas já montadas, uma mudança no processo de produção ou fluxo do serviço, introdução de novos produtos ou serviços, a necessidade de redução de custos, a expansão de uma seção, etc. podem levar à necessidade de uma modificação no layout, devendo para isso estudar o melhor tipo a ser aplicado à sua situação. Assim, os Arranjos Físicos podem ser classificados como:

a) O arranjo físico Posicional conforme Martins e Laugeni (1999, p.112), “O material permanece fixo em uma determinada posição e as máquinas se deslocam até o local executando as operações necessárias”.

Algumas características deste tipo de arranjo físico: não é repetitivo, para um produto único, em quantidade pequena ou até unitária e minimiza a quantidade necessária de movimento de produto (GAITER e IRAZIER, 2001). Como exemplo pode-se mencionar a construção de uma rodovia ou um estaleiro, sendo o produto grande para ser movido. Também podemos citar um restaurante onde os clientes prefeririam ficar em um determinado lugar e a comida ter que ser 
movida até eles, ou então uma cirurgia onde o estado do paciente não permite uma remoção de lugar (SLACK et al, 1999).

b) Arranjo Físico por Processo tem esta denominação, pois, de acordo com Slack et al (1999, p.164), "as necessidades e as conveniências dos recursos transformadores que constituem o processo na operação dominam a decisão sobre o arranjo físico“. Este tipo de arranjo mantém todos os recursos similares da operação próximos um do outro, isto é mais conveniente para que desta forma a utilização dos recursos transformadores seja otimizada.

É normalmente utilizado quando há uma variedade relativamente alta de produtos ou clientes que percorrerão roteiros diferentes através da operação, tornando o fluxo de operação complexo (SLACK et al, 1999). Para Martins e Laugeni (1999), este processo apresenta as seguintes características: flexibilidade para atender as mudanças no mercado, fluxo longo dentro da fábrica, possibilita satisfação no trabalho, mais adequado para produções diversificadas em médias ou pequenas quantidades e atende a produtos diversificados ao longo do tempo. Temos como exemplo deste tipo de layout um supermercado, um hospital ou também uma biblioteca, onde se procura dispor produtos ou serviços similares juntos para aperfeiçoar a operação (SLACK et al, 1999).

c) Arranjo Físico Celular é assim chamado por que os recursos necessários para uma operação específica estão dispostos de forma agrupada, ou seja, consiste em dispor em um só local as máquinas ou equipamentos que serão utilizados para a fabricação do produto inteiro.

Conforme Slack et al (1999, p.165), "De fato, o arranjo físico celular é uma tentativa de trazer alguma ordem para a complexidade de fluxo que caracteriza o arranjo físico por processo". Apresenta as seguintes características: flexibilidade quanto ao tamanho de lotes por produto, específico para a mesma linha de produtos, redução com transporte de materiais, redução dos estoques, elevado nível de qualidade e produtividade, centralização da responsabilidade sobre o produto de fabricação (MARTINS e LAUGENI, 1999).

Como exemplo tem a maternidade de um hospital onde pacientes que necessitam deste atendimento formam um grupo para serem atendidos juntos, pois dificilmente precisarão de atendimento em outros setores do hospital e ao mesmo tempo precisam de cuidados do setor de maternidade. (SLACK et al, 1999).

d) Arranjo por Produto implica em localizar os recursos de transformação de acordo com a conveniência do recurso que está sendo transformado. De acordo com Martins e Laugeni (1999, p.111), “As máquinas ou as estações de trabalho são colocadas de acordo com a seqüência das operações e são executadas de acordo com a seqüência estabelecida sem caminhos alternativos". O produto possui um caminho determinado no processo. É um arranjo de fácil controle, pois o fluxo de clientes, informações e produtos são claro e previsível. 
Características: para produção sem diversificação, investimento elevado em máquinas, pode vir a gerar monotonia ou estresse nos operadores e pode apresentar problemas em relação à quantidade de produtos fabricados (MARTINS e LAUGENI, 1999).

Alguns exemplos de arranjo físico por produto: montagem de automóveis, que necessitam da mesma seqüência de processos (para um mesmo modelo de automóvel), restaurantes self-service nos qual a sequiência de serviço é comum para todos os clientes, mas o arranjo ajuda a manter o controle sobre o fluxo dos mesmos (SLACK et al, 1999).

e) Arranjo Físico Misto ou Combinado é uma combinação de outros tipos de arranjos físicos. (SLACK et al, 1999). Os departamentos são organizados de acordo com os tipos de processos, mas o produto flui através de um layout por produto. Como exemplo: um hospital que geralmente possui um arranjo físico por processo, sendo que em seus departamentos, como a radiologia, usa-se provavelmente o arranjo físico por processo, as salas cirúrgicas normalmente por posição e o laboratório de processamento de sangue é arranjado por produto, conforme Slack et al (1999). Para os mesmos autores (1999, p.176), “O fluxo de pessoas, informações e materiais através da operação é determinado pelo tipo de arranjo físico escolhido. Num extremo, em arranjo físico posicional, o fluxo é intermitente. No outro extremo, no arranjo físico por produto, o fluxo torna-se mais contínuo".

\subsection{Teoria das restrições e perdas}

A Teoria das Restrições foca o aperfeiçoamento do sistema como um todo. Assim, o sistema compreende vários processos interdependentes, de tal forma que se assemelha à uma corrente na qual todos os elos trabalham na mesma direção e objetivo. O elo mais fraco da corrente é a restrição. Portanto a Teoria das Restrições concentra-se na atividade ou processo que reduz a velocidade da produção dentro de um sistema.

A Teoria das Restrições, também denominada de TOC (Theory of Constraints) é um desenvolvimento relativamente recente no aspecto prático da tomada de diversas decisões organizacionais nas quais existem restrições.

Uma restrição é qualquer fator numa empresa que a impede ou limita seu movimento em direção aos seus objetivos. É claro que a aplicação da TOC requer uma apropriada definição dos objetivos a serem atingidos. Para a maior parte das empresas, o objetivo principal é o lucro presente e sua sustentabilidade no futuro. Existem dois tipos básicos de restrições: físicas e não-físicas. As restrições físicas na maior parte das vezes estão relacionadas a recursos: máquinas, equipamentos, veículos, instalações, sistemas etc. As restrições não-físicas podem ser a demanda por um produto, um procedimento corporativo ou mesmo um paradigma mental no encaminhamento de um problema. (WANKE, 2006): 
A TOC tem sido aplicada em três diferentes níveis de tomada de decisão: gerência da produção, na resolução de problemas relacionados aos gargalos, à programação e à redução dos estoques; análise de rentabilidade, levando à mudança de decisões baseadas em custo para decisões baseadas na melhoria contínua das operações que afetam a rentabilidade; e, gestão de processos, na identificação de fatores organizacionais, que não são necessariamente recursos, que impedem as empresas de atingirem seus objetivos.

Para Corbett (2006) uma das grandes contribuições da TOC é o seu processo de otimização contínua e contém 5 etapas: Identificar a restrição do sistema, Explorar a restrição do sistema, Subordinar tudo o mais à decisão acima e Elevar a restrição do sistema.

Se num passo anterior a restrição for quebrada, volte ao passo um. Mas não deixe que a inércia se torne a restrição do sistema. Usando esse processo podem-se enfocar os esforços nos poucos pontos de um sistema que apresentam baixo desempenho ou restrição e assim podemos melhorar significativamente seu desempenho no curto prazo.

Os autores, acima citados, sustentam que a Teoria das Restrições melhora o tempo de fluxo no sistema, reduz o desperdício, aumenta o índice de saída e melhora os tempos de ciclo. Além disso, argumentam que o foco na restrição não exige um conhecimento mais profundo de análise de dados. Cabe ao gestor identificar a restrição e criar condições para que ela deixe de ser o empecilho ao alcance do objetivo da empresa. Quando se identifica e se elimina a restrição, cria-se automaticamente outra que será o novo alvo da melhoria no sistema, portanto os esforços gerenciais estarão sempre concentrados nos gargalos elevando a capacidade de produção da empresa e evitando perdas.

A perda é definida como a parcela de recursos utilizados de forma não necessária. Bornia (1997) define perda como "Tudo o que não agrega valor ao produto e custa alguma coisa, desde materiais e produtos defeituosos até atividades não produtivas". Mas, nem todas as atividades nãoprodutivas podem ser eliminadas completamente, tais como preparação de máquinas, movimentação de matérias. No entanto, podem ser otimizadas.

O trabalho que agrega valor, também denominado de trabalho efetivo, refere-se a todas as atividades de transformação. $\mathrm{O}$ trabalho que não agrega valor ma serve como suporte ao trabalho efetivo, é denominado de trabalho adicional. Já o trabalho que não agrega valor e, também, não é necessário ao trabalho efetivo, é dado como desperdício. Dentro dessa categoria tem-se a produção de itens defeituosos, a movimentação desnecessária, a capacidade ociosa, etc.

Shingo apud Bornia (1997) propõe sete grandes classes de perdas: perdas por superprodução, transporte, processamento em si, fabricação de produtos defeituosos, movimentação, espera e estoque. Uma redução contínua das perdas levará a empresa a baixar os custos de produção de seus produtos. Além disso, irá propiciar o aperfeiçoamento geral de seus 
processos e, conseqüentemente, haverá melhoria dos produtos. À medida que os desperdícios vão sendo diminuídos, novos padrões de desempenho são alcançados. De acordo com Nakagawa (1993), a eliminação de todas as formas de desperdício levará a empresa a melhorar a produtividade e a qualidade e auxiliará na redução de custos. Tudo isso contribuirá para torná-la mais competitiva.

\section{Metodologia}

O presente trabalho utilizou-se uma metodologia em que se procurou viabilizar as técnicas de investigação, recorrendo-se, simultaneamente, a informações documentais e não documentais, um estudo de caso. Conforme Cervo (1996), o método é a ordem que se deve impor aos diferentes processos necessários para atingir um dado fim ou um resultado desejado e metodologia é o estudo do conjunto de processos que o espírito humano deve empregar para a investigação e demonstração da verdade.

Para formulação de um referencial teórico que possa ser utilizado para repensar a situação das organizações em relação ao sistema de produção, em um primeiro momento, buscaram-se informações referentes ao assunto em estudo, em referências bibliográficas como livros, artigos, reportagens, e sites. Realizando-se assim uma pesquisa bibliográfica.

De acordo com Lakatos e Marconi (1992) a pesquisa bibliográfica não é mera repetição do que já foi dito ou escrito sobre um determinado contexto, mas propicia a análise de um tema sob novo enfoque ou abordagem, chegando deste modo a conclusões inovadoras.

Em um segundo momento, tornou-se necessário realizar uma confirmação entre o referencial teórico construído e a realidade do sistema de produção na empresa Mor, para isso foi realizada uma pesquisa de campo, observacional, do tipo descritiva e exploratória, na qual se utilizou entrevista que serviram de suporte para se chegar aos resultados obtidos.

Segundo Bastos e Keller (1992) a pesquisa de campo visa suprimir dúvidas, ou obter informações e conhecimentos a respeito de problemas para as quais se procura resposta ou a busca de confirmação para hipóteses levantadas e, finalmente, a descoberta de relações entre fenômenos ou os próprios fatos novos e suas respectivas explicações.

Conforme Gil (1991) a pesquisa exploratória visa proporcionar maior familiaridade com o problema com vistas a torná-lo explícito ou a construir hipóteses. Envolvem levantamento bibliográfico; entrevistas com pessoas que tiveram experiências práticas com o problema pesquisado; análise de exemplos que estimulem a compreensão. O presente estudo limitou-se em analisar e contribuir para diminuição, e até mesmo para a eliminação, do gargalo existente na fabricação das escadas de aço e alumínio na empresa metalúrgica. 


\section{Análises dos resultados}

Para obtenção dos resultados observou-se que a empresa, em função do fluxo do produto, apresenta um sistema contínuo, pois existe uma seqüência linear em sua produção. São constatados três tipos de manufatura: automática, semi-automática e manual.

Em relação ao tipo de Layout utilizado constatou-se que na empresa, em sua estrutura geral, no pavilhão de produção apresenta um layout de manufatura celular. A fábrica é dividida em células de produção totalmente independentes que abrigam cada linha de produtos, ou seja, célula de fabricação das panelas, escadas, cadeiras, etc.

Dentro de cada célula produtiva o arranjo físico por produto, uma vez que requer uma seqüência linear de operações, sistema contínuo. Encontram-se assim as principais características: produtos padronizados, programação estável e previsível, com equipamentos especializados e especialmente projetados para altos volumes, requerendo uma rotina simplificada de operações. O faturamento da empresa está baseado em aproximadamente $30 \%$ na comercialização de cadeiras, $30 \%$ de piscinas, $5 \%$ de escadas e $35 \%$ demais linhas de produtos, sendo que $25 \%$ a $30 \%$ das escadas fabricadas vão para o mercado externo. A empresa vende seus produtos nos mais variados ramos de distribuidoras e comércio, como: redes de supermercados, redes atacadistas, lojas de artigos de camping e eletrodomésticos.

\subsection{Informações levantadas para a execução do processo de melhoria}

Para se analisar o processo de fabricação das escadas de aço e de alumínio, a fim de averiguar o ponto crítico de todo o processo e com isto propor uma melhoria, foi feito primeiramente, um macrofluxo conforme Figura 1. A partir da análise do macrofluxo e da fabricação in loco, constatou-se que o gargalo se encontra na montagem do conjunto da moldura com os degraus e a plataforma, assim foi dado um especial destaque a este ponto do fluxo, já que a empresa é realmente tem grande interesse em resolver este problema. 
Figura 1 - Macrofluxo Processo Produtivo - Escadas de aço e alumínio

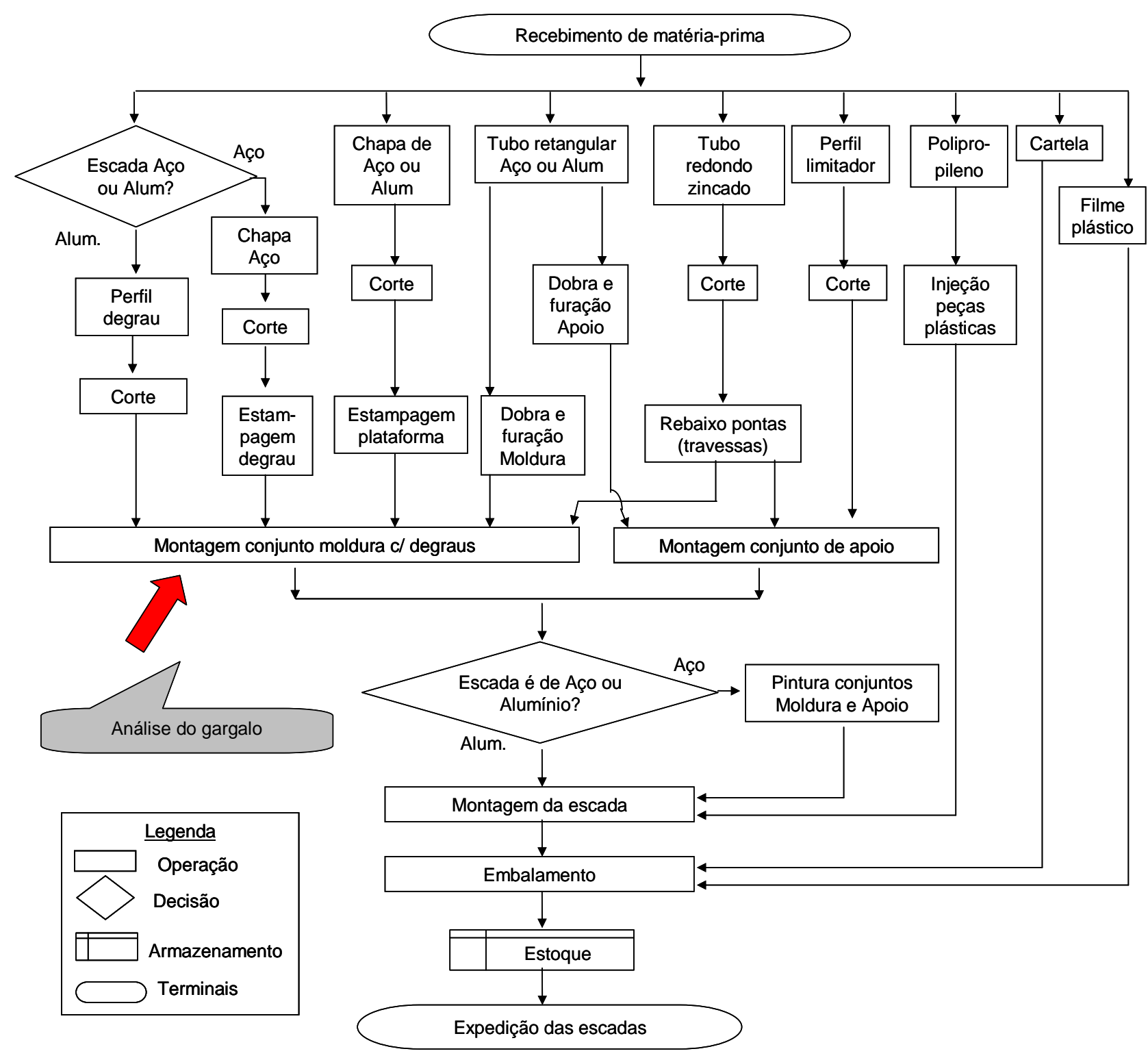

Fonte: Dados da própria empresa

Após a elaboração do macrofluxo redirecionou-se o foco do estudo para a montagem do conjunto da moldura com os degraus e a plataforma, onde foi feito um microfluxo para ressaltar o ponto mais comprometedor do processo, de acordo com a Figura 2. Somente com estes dados iniciais é que foi possível trabalhar com maior clareza para que se pudessem sugerir melhorias neste processo de fabricação. 
Figura 2 - Microfluxo montagem conjunto moldura com degraus e plataforma

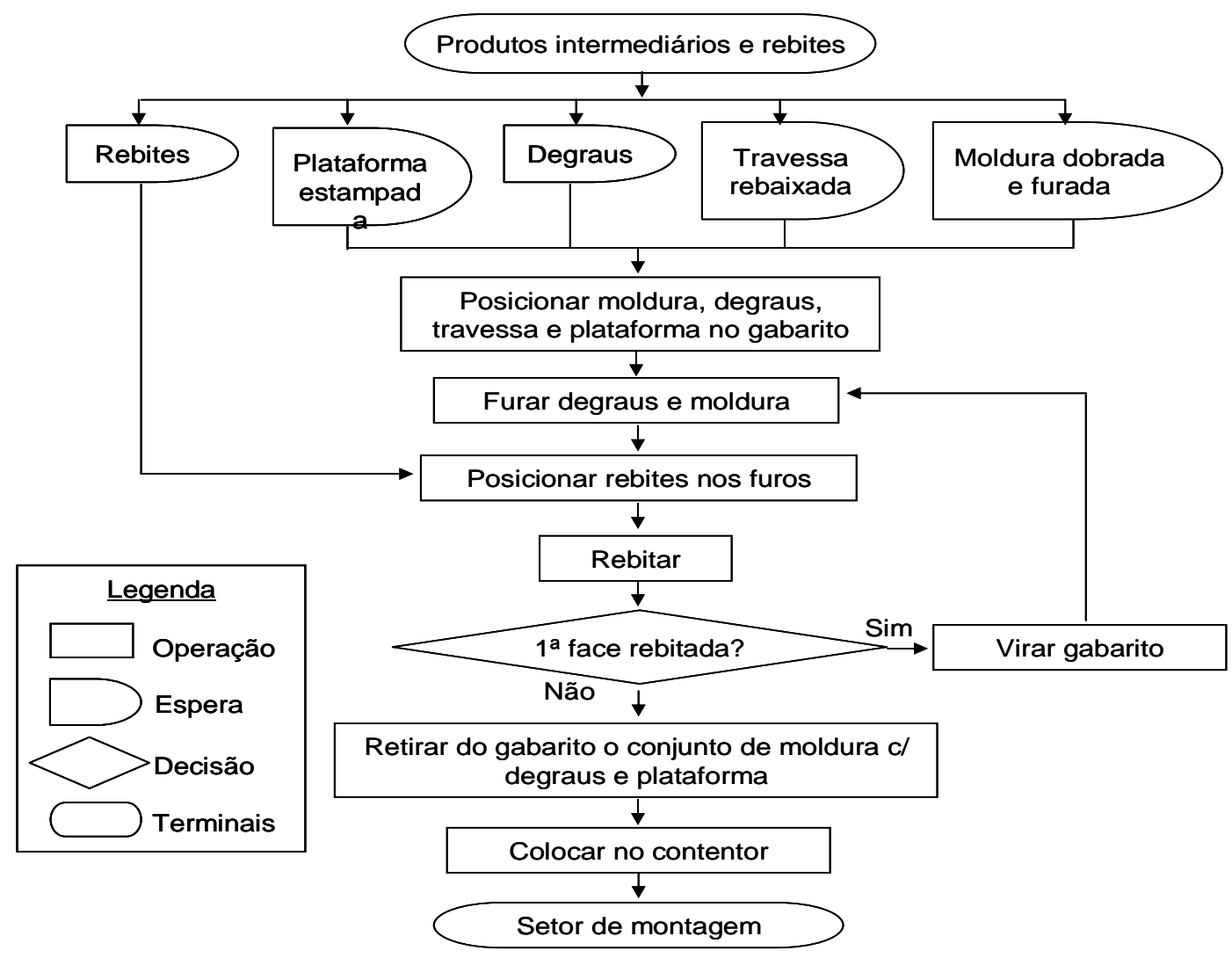

Fonte: Dados da própria empresa

A partir deste passo inicial, foi feita uma análise de algumas etapas de todo o processo de fabricação das escadas, conforme mostra o quadro 1. Os números mostrados no Quadro 1, são a produção de peças por hora por pessoa, sendo selecionados somente algumas etapas relevantes e as que possuíam a menor produção por hora. Desta forma, verificou-se matematicamente o quanto este gargalo estava prejudicando o andamento da produção, ficando claro um dos menores tempos de produção era montagem do conjunto da moldura com os degraus e a plataforma. Apesar de, na etapa de montagem da escada a produção por hora por pessoa ser ainda menor, a justificativa em selecionar a etapa em questão ( $\mathrm{n}^{\circ} 3$ no quadro 1) é a empresa contar com apenas um gabarito trabalhando duas pessoas, enquanto na montagem da escada estão trabalhando oito pessoas.

Quadro 1: Etapas relevantes do processo de produção das escadas x média de hora/homem

\begin{tabular}{|c|l|c|c|}
\hline $\mathbf{N}^{\mathbf{0}}$ & \multicolumn{1}{|c|}{ Processos } & Média /AÇO & Média /ALUMINIO \\
\hline 1 & Embalar escada & 36,14 & 38,83 \\
\hline 2 & Montar escada & 12,13 & 11,96 \\
\hline 3 & $\begin{array}{l}\text { Montagem moldura c/ degraus e } \\
\text { plataforma }\end{array}$ & $\mathbf{1 3 , 0 0}$ & $\mathbf{1 3 , 0 0}$ \\
\hline 4 & Dobra e furação moldura & 160,00 & 80,83 \\
\hline 5 & Montagem apoio & 74,67 & 81,00 \\
\hline 6 & Dobra e furação apoio & 270,00 & 160,00 \\
\hline
\end{tabular}




\subsection{Alternativas de melhoria}

Através da Técnica C.I.A. (Conhecer / Identificar / Agir) conforme quadro 2 e Técnica GUT (Gravidade/ Urgência/Tendência) no quadro 3 desenvolveu-se meios para traçar alternativas de melhoria no processo encontrado.

A partir da técnica C.I.A., tomou-se consciência de como conhecer os pontos fracos do processo, identificando-os e fazendo uma análise detalhada de melhoria, viabilidade técnica e econômica. Através do método G.U.T., foram priorizadas e foco para ações de melhorias no processo (pontos mais prejudiciais no processo).

Quadro 2: Técnica C.I.A. aplicada ao estudo

\begin{tabular}{|l|l|l|}
\hline \multicolumn{1}{|c|}{ CONHECER } & \multicolumn{1}{c|}{ IDENTIFICAR } & \multicolumn{1}{c|}{ AGIR } \\
\hline C1 - Empresa & I1 - Macrofluxo do processo & A1 - Alternativas de melhoria no \\
C2 - Produtos & I2 - Microfluxo do processo \\
C3 - Processo produtivo Escadas & I3 - Atividade crítica & A2 - Análise de viabilidade de cada \\
C3 - Especificações & pelo método GUT & $\begin{array}{l}\text { alternativa } \\
\text { A3 - Implementar a melhoria escolhida } \\
\text { A4 - Acompanhar desempenho }\end{array}$ \\
& & \\
& & \\
\hline
\end{tabular}

Conforme se observa no Quadro 3, o processo de prioridade foi o de furar degraus e moldura, seguidos do processo de rebitagem e posicionamento dos rebites nos furos.

Quadro 3: Análise de atividade crítica - Método G.U.T.

\begin{tabular}{|l|c|c|c|c|c|}
\hline \multicolumn{1}{|c|}{ Processo } & G & U & T & V.A. & Prioridade \\
\hline Posicionar peças no gabarito & 3 & 2 & 2 & 12 & $5^{\text {a }}$ \\
\hline Furar degraus e moldura & $\mathbf{5}$ & $\mathbf{5}$ & $\mathbf{4}$ & $\mathbf{8 0}$ & $\mathbf{1}^{\mathbf{a}}$ \\
\hline Posicionar rebites nos furos & 3 & 3 & 3 & 27 & $3^{\mathrm{a}}$ \\
\hline Rebitar & 4 & 4 & 3 & 18 & $2^{\mathrm{a}}$ \\
\hline Virar gabarito & 3 & 3 & 3 & 18 & $4^{\mathrm{a}}$ \\
\hline Retirar conjunto de moldura c/ degrau do gabarito & 2 & 2 & 2 & 8 & $6^{\mathrm{a}}$ \\
\hline Colocar conjunto no contentor & 1 & 2 & 1 & 2 & $7^{\mathrm{a}}$ \\
\hline
\end{tabular}

Com os dados levantados, foram propostas algumas alternativas de melhoria com o intuito de que o gargalo existente diminuísse consideravelmente. Foram s alternativas levantadas sete alternativas, que foram apresentadas ao departamento de engenharia da empresa e feita uma análise criteriosa de cada uma:

1) Fazer furação com duas furadeiras: Conforme figura 3, onde mostra lateralmente a moldura com o degrau, a idéia é de fazer a furação com duas furadeiras simultaneamente furando de cima para baixo e de baixo para cima. Fazer um dispositivo adaptado ao gabarito para que se mova nas laterais, sendo o processo de furação feito em apenas uma etapa ao invés de duas. Para poder 
implementar a alternativa foi estimado um investimento de $\mathrm{R} \$ 3.500,00$ ( 2 × R \$ 750,00 furadeiras + R \$ 2.000,00 adaptação mecânica), tendo uma redução média no custo de R \$ 0,33/escada, e uma economia anual de $\mathrm{R} \$ 26.200,00$ sendo o retorno do investimento em apenas 1,5 meses. Pelo baixo investimento e retorno rápido, esta seria uma ótima opção.

2) Fazer furação simultânea de todos os furos de cada lado da moldura no gabarito: Esta segunda alternativa de melhoria exigiria muitas furadeiras, com um custo de manutenção relativamente alto, com um alinhamento complexo e que exigira uma estrutura muito grande de adaptação. Na figura 4, pode-se ter uma idéia da quantidade de furos simultâneos, levando-se em conta que para a maior escada ( 8 degraus) seriam 16 furos simultâneos. Por isto tudo, esta não seria uma boa alternativa.

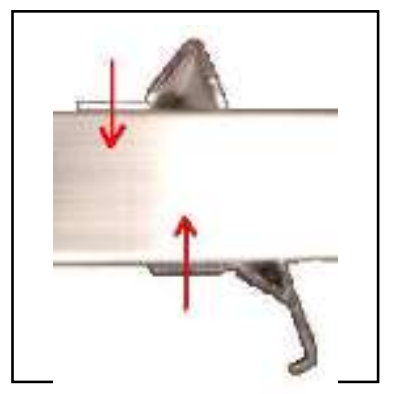

Figura 3

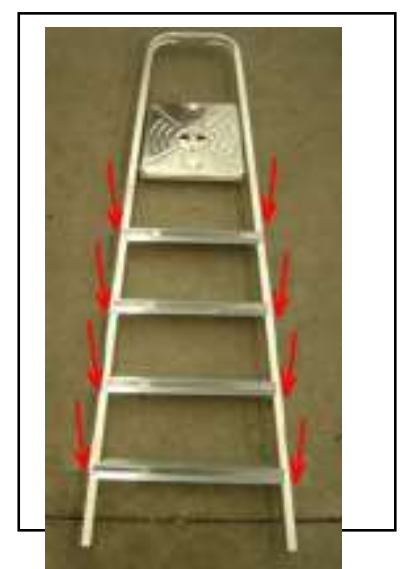

Figura 4 - Escadas de 5 degraus

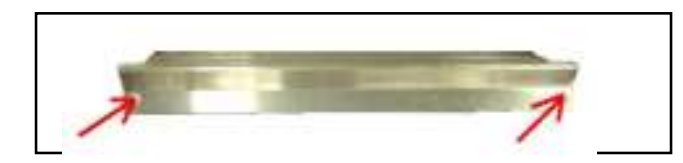

Figura 5

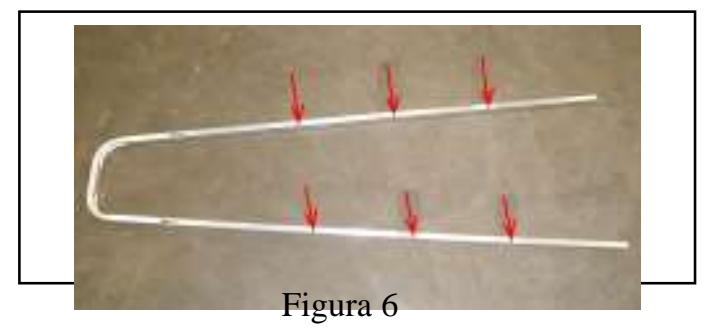

3) Fazer furos na moldura e nos degraus separadamente, após rebitar: A idéia seria de fazer as furações na moldura durante o processo de dobra e nos degraus durante seu corte (alumínio) ou estampagem (aço). Esta alternativa exigiria grande precisão dimensional, um alinhamento complexo e o gabarito existente não condizem com este padrão, às figuras 5 e 6 mostram as furações. Esta terceira alternativa não seria uma boa melhoria.

4) Fazer furos passantes na diagonal: Analisando a figura 7, esta ação de melhoria também exige precisão dimensional dos furos, complexa adaptação para furar na diagonal e grande desgaste das furadeiras. O furo ficará oval e o rebite não ficará bem fixado. Por isto, esta também não seria uma boa alternativa.

5) Acrescentar uma pessoa a mais no processo para posicionar os rebites: A quinta ação de melhoria a ser estudada visa o aumento de duas para três pessoas na linha de produção, para que esta posicione os rebites conforme a pessoa da frente estaria fazendo a furação. Ficou evidente que esta pessoa atrapalharia no processo e que não proporcionaria ganhos significativos de produtividade, inviabilizando esta ação. Atualmente existem duas pessoas trabalhando no processo 
de montagem do conjunto da moldura com os degraus, ficando um operador de cada lado, como mostra a figura 9.

6) Dispositivo automático de alimentação de rebites: esta alternativa de melhoria considerada foi de adquirir um dispositivo automático de alimentação de rebites para auxiliar na etapa de posicionamento dos rebites nos furos. O investimento necessário seria de $\mathrm{R} \$ 4.800,00$ (R $\$$ 4.300,00 alimentador $+\mathrm{R} \$ 500,00$ adaptações), porém não haveriam ganhos significativos de produção, sendo desconsiderada esta alternativa.

7) Automatizar o processo: Verificou-se que para automatizar o processo seria necessário aumentar a "aba" do perfil podendo-se fazer furos passantes e substituir os rebites pop por semitubulares, conforme figura 8. Uma análise de viabilidade econômica foi feita, levando-se em conta o aumento de custo devido ao aumento de material da "aba" e redução de custo por acréscimo em 50\% de produtividade, assim como, uma redução de duas pessoas na linha. Atualmente existem duas pessoas que cuidam da etapa da dobra da moldura e, que é feita anteriormente à montagem do conjunto e já automatizada, esta etapa tem maior produção sendo as molduras dobradas acumuladas. A redução de pessoas se deve ao fato de que a sugestão é de colocar uma máquina automática logo após a dobra da moldura, fazendo com que elas não se acumulem mais, tendo apenas as mesmas duas pessoas no total para cuidar desta etapa ao invés de quatro, como é atualmente. Foi feito um levantamento de investimento de $\mathrm{R} \$ 105.000,00$. Com isto, haveria uma redução média de $\mathrm{R} \$$ 0,99/escada e uma economia anual de $\mathrm{R} \$$ 80.000,00 com retorno do investimento em 1,24 anos.

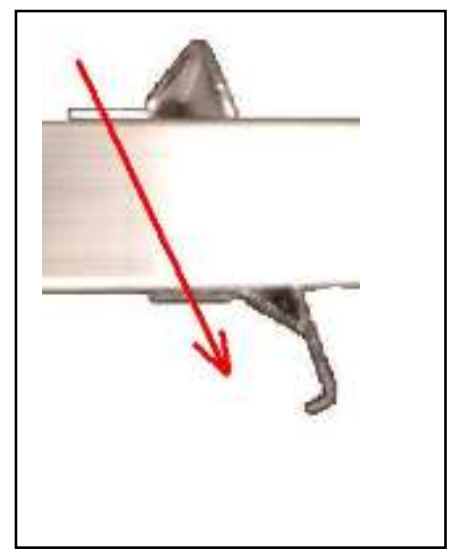

Figura 7

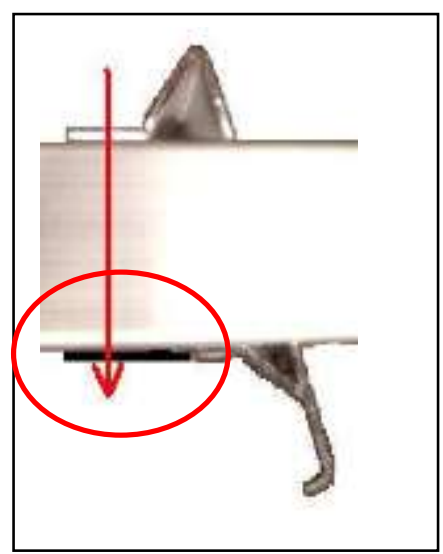

Figura 8

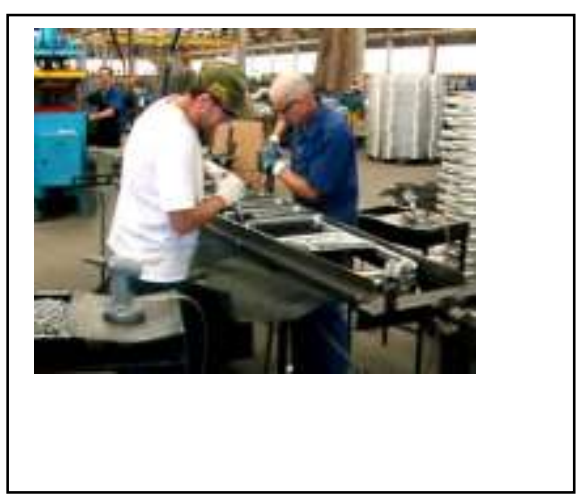

Figura 9

As análises feitas das ações de melhoria desenvolvidas são de que as alternativas de número sete e um serão as mais acertadas. A alternativa sete tem retorno de investimento de 1,24 anos e uma economia anual de $\mathrm{R} \$ 80.000,00$. Esta alternativa eliminaria o gargalo, mas para ser colocada em prática deverão ser feitos testes de resistência do degrau. Já a alternativa um tem baixo investimento, retorno em 1,5 meses e economia anual de $\mathrm{R} \$ 26.200,00$, não exigindo testes de 
resistência. Serão apresentadas todas as conclusões a cerca das alternativas de melhoria à empresa interessada, cabe à mesma julgar a solução mais condizente com a sua política e a sua situação atual no mercado.

\title{
5. Conclusão
}

Diante do fato de que a produção de uma empresa deve ser capaz de satisfazer as necessidades dos consumidores, o planejamento da produção deve se preocupar com o operar dos recursos de modo a fornecer bens e serviços que satisfarão as suas exigências. Por isso o administrador da produção deve ser capaz de compatibilizar os recursos produtivos da empresa, visando atender os prazos previstos com o menor custo possível. Há de levar em conta os diversos aspectos que interferem na vida da empresa e na sua operacionalidade, como, por exemplo, o arranjo físico e sistema de produção, as possíveis perdas e gargalos.

Após estudar a parte teórica de um processo de fabricação industrial, levantar dados relevantes, fazer e analisar o macro e microfluxo da produção, utilizar técnicas C.I. A (Conhecer/ Identificar/ Agir) e G.U.T. (Gravidade /Urgência/ Tendência), para a solução de problemas de gargalo envolvendo o setor da produção de escadas, ficou evidente de como se deve proceder no desenvolvimento de ações de melhoria e estipular planos de ação.

Foram necessários diversos contatos com a empresa, com os responsáveis pela produção, manutenção e setor de projetos para se chegar a estas sete ações de melhoria que foram estabelecidas e desenvolver o diagnóstico. Através deste trabalho inicial, que será levada a diretoria da empresa, é que vão ser colocadas realmente em prática as ações consideradas melhores em termos de rentabilidade e produtividade. Pois a direção vai analisar somente ações que tiverem uma taxa de retorno com menos de dois anos da implementação.

Este estudo realizado mostrou-se extremamente válido por estar voltado a realidade industrial e com um ponto crucial, juntar a teoria estudada na vida acadêmica com a prática organizacional com a proposta de buscar soluções a problemas reais.

\begin{abstract}
s
The main objective of this study is to present an improvement proposal associated with the productive process of the aluminum and steel stairs produced in a metallurgic company, aiming the reduction and even though the elimination of bottlenecks. The adopted method of the research is characterized as being exploratory and descriptive, in the data survey it was used the observation and the analysis in the production sector of the company, as well as interviews with the production manager that had served as a support to get the results. Through the analysis of the data, the development of improvement alternatives was possible. But the choice of the best proposal fits to the company's direction, in the economic and operational ways. Beyond reaching the considered
\end{abstract}


objective, the study provided the confrontation of the theory with the organizational practice, being an aspect of utmost importance for learning in the academic life.

Key-words: Production, Bottleneck, Improvements alternatives

\section{Referências bibliográficas}

BASTOS, C.; KELLER, V. Aprendendo a aprender: introdução à metodologia Científica. 3. ed. Petrópolis: Vozes. 1992.

BORNIA, A.C. Custos Industriais (Apostila): UFSC - Programa de Pós- Graduação em Engenharia de Produção, 1997.

CORBETT, T. Teoria das Restrições. Disponível em: <www.corbett.pro.br〉. Acesso em 22 maio, 2006.

CERVO, A.L. Metodologia cientifica. 4 ed. São Paulo: Makron Books, 1996.

DAVIS, M. M.; AQUILANO, N. J.; CHASE, R. B. Fundamentos da administração da produção. 3. ed. São Paulo: Bookman Editora, 2001.

GAITHER, N; FRAZIER, G. Administração da produção e operações. São Paulo: Pioneira, 2001.

GIL, A.C. Métodos e técnicas de pesquisa social. $5^{\text {a }}$ ed. São Paulo: Atlas, 1999.

LAKATOS, E.M ; MARCONI, M. A. Metodologia do trabalho científico: procedimentos básicos, pesquisas bibliográfica, projeto e relatório, publicações e trabalhos científicos. 4. ed. São Paulo: Atlas. 1992.

MARTINS, P. G.; LAUGENI, F. P. Administração da Produção. São Paulo: Editora Saraiva 1999.

MOREIRA, D. A. Administração da produção e operações. 5. ed. São Paulo: Pioneira, 2000.

NAKAGAWA, M. Gestão estratégica de custos: conceito, sistemas e implementação. São Paulo: Atlas, 1993.

RUSSOMANO, Victor Henrique. Planejamento e controle da produção. 6. ed. São Paulo: Pioneira, 2000.

SLACK, N. et al. Administração da produção. São Paulo: Editora Atlas SA, 1999.

WANKE, P, Gestão de Estoques na Cadeia de Suprimentos - Decisões e Modelos Quantitativos. São Paulo: Editor Atlas, 2003.

\section{Os autores:}

Nome completo: Claudete Fogliato Ribeiro. Adriane Guarienti e Marcia Trojan Poll

Filiação institucional: Mestrandas do Programa de Pós-graduação em Engenharia de Produção

Departamento:PPGEP - UFSM

Função ou cargo ocupado: mestranda

Endereço completo para correspondência (bairro, cidade, estado, país e CEP):

Marechal Rondom 297. Salgado Filho. Santa Maria. RS.

Telefones para contato:55 32253774 / 5599764925

e-mail:claufr@terra.com.br/ adrig.sm@terra.com.br/marcia@ mor.com.br / jholive@ terra.com.br 
Nome: Professor Dr. João Hélvio R. Oliveira

Filiação institucional: docente

Departamento: PPGEP - UFSM

Função ou cargo ocupado: Professor orientador

Santa Maria - RS

Fone/Fax: + 5532208619

E-mail: ppgep@ct.ufsm.br

Recebido para publicação em: 18/04/07

Aceito para publicação em: 03/05/07 